\title{
APPROXIMATION OF THE NUMERICAL RANGE OF POLYNOMIAL OPERATOR MATRICES
}

\author{
AHMED MUHAMMAD
}

Abstract. A linear operator on a Hilbert space may be approximated by finite matrices choosing an orthonormal basis of the Hilbert space. In this paper we establish an approximation of the $q$-numerical range of a bounded and an unbounded polynomial operator by variational methods. Applications to Hain-Lüst operator and Stokes operator are also given.

Mathematics subject classification (2020): 47A58, 47A20, 47A12, 15A60.

Keywords and phrases: Polynomial operator, $q$-numerical range, projection method, Hain-Lüst operator, Stokes operator.

\section{REFERENCES}

[1] A. Munammad, Approximation of quadratic numerical range of block operator matrices, Ph. D. thesis, Cardiff University, (2012).

[2] M. AdAM AND P. PSARRAKOS, On a compression of normal matrix polynomials, Linear and Multilinear Algebra, 52 (3-4), (2004), 251-263.

[3] V. M. ADAMJAN, H. LANGER, Spectral properties of a class of rational operator valued functions, J. Operator Theory 33 (1995), 259-277.

[4] D. E. Edmunds And W. D. Evans, Spectral theory and differential operators, Oxford University Press, New York, 1987.

[5] M. T. ChiEn, H. NAKAZATO AND P. PSARRAKOs, On the q-numerical range of matrices and matrix polynomials, Linear and Multilinear Algebra, 53(5), (2005), 357-374.

[6] C. S. KUBRUSLY, Hilbert space operators, a problem solving approach, Birkher Boston, Inc., Boston, MA, 2003.

[7] K. Schmdgen, Unbounded Self-adjoint Operators on Hilbert Space, Springer, GTM 265 (2012).

[8] F. Gantmacher, The Theory of Matrices, Chelsea, New York, 1959.

[9] I. Gohberg, P. Lancaster And L. Rodman, Matrix Polynomials, Academic Press, New York, 1982.

[10] K. HAIN AND R. LÜST, Zur Stabilität zylindersymmetrischer Plasmakonfigurationen mit Volumenströmmen, Z. Naturforsch. 13, (1958), 936-940.

[11] I. IstRATESCU, Introduction to linear operator theory, Marcel Dekker, New York, 1982.

[12] H. Langer, R. Mennicken, M. MöLler, A second order differential operator depending nonlinearly on the eigenvalue parameter, Oper. Theory Adv. Appl., 48, Birkhäuser, Basel (1990), pp. 319-332.

[13] H. LANGER AND C. TRETTER, Spectral decomposition of some nonselfadjoint block operator matrices, J. Operator Theory, 39, (1998), 339-359.

[14] C. K. Li AND L. Rodman, Numerical range of matrix polynomials, SIAM J. Matrix Anal. Appl. 15, (1994), 1256-1265.

[15] A. S. MARKus, Introduction to the Spectral Theory of Polynomial Operator Pencils, Transl. Math. Monogr., 71, Amer. Math. Soc., Providence, RI, 1988.

[16] M. Marletta AND C. TRETTER, Essential spectra of coupled system of differential equations and applications in hydrodynamics, J. Differential Equations, 243, (2007), 36-69.

[17] J. Maroulas And M. AdAM, Compressions and Dilations of Numerical Ranges, SIAM J. on Matrix Analysis and Applics, 21 (1), (1999), 230-244. 
[18] P. H. MüLLER, Über Eine Klass Von Eigen Wertaufgaben Mit Nichtlinearer parameter-abhangigkeit, Math. Nachr. 12, (1954), 173-181.

[19] P. PSARRAKOS, On the estimation of the q-numerical range of monic matrix polynomials, Electronic Transactions on Numerical Analysis (ETNA), 17, (2004), 1-10.

[20] P. PSARRAKos, The q-numerical range of matrix polynomials II, Bull. Greek Math. Soc., 45, (2001), 3-15.

[21] P. PSARRakos And P. Vlamos, The q-numerical range of matrix polynomials, Linear and Multilinear Algebra, 47, (2000), 1-9.

[22] P. PSARRAKOS, http://www.math.ntua.gr/ ppsarr/polrange.m.

[23] L. Rodman, An introduction to operator polynomials, Oper. Theory Adv. Appl. Birkhäuser Verlag, Berlin 1989.

[24] C. TRetTer, Spectral theory of block operator matrices and Application, Imperial College Press, London (2008). 